\title{
Genetic structure and clonal diversity of an introduced pest in Chile, the cereal aphid Sitobion avenae
}

\author{
CC Figueroa ${ }^{1}$, J-C Simon ${ }^{2}$, J-F Le Gallic ${ }^{2}$, N Prunier-Leterme ${ }^{2}$, LM Briones ${ }^{1}$, C-A Dedryver ${ }^{2}$ \\ and HM Niemeyer ${ }^{3}$ \\ ${ }^{1}$ Instituto de Ecología y Evolución, Universidad Austral de Chile, Campus Isla Teja. Casilla 567, Valdivia, Chile; ${ }^{2}$ UMR INRA/ \\ Agrocampus Rennes 'Biologie des Organismes et des Populations appliquée à la Protection des Plantes' [BIO3P] BP 35327, 35653 Le \\ Rheu Cedex, France; 'BDepartamento de Ciencias Ecológicas, Facultad de Ciencias, Universidad de Chile, Casilla 653, Santiago, Chile
}

In Chile, the aphid Sitobion avenae is of recent introduction, lives on cultivated and wild Poaceae, and is thought to reproduce by permanent parthenogenesis. In order to study the genetic variability and population structure of this species, five microsatellite loci were typed from individual aphids collected from different cultivated and wild host plants, from different geographical zones, and years. Chilean populations showed a high degree of heterozygosity and a low genetic variability across regions and years, with four predominant genotypes representing nearly $90 \%$ of the sample. This pattern of low clonal diversity and high heterozygosity was interpreted as the result of recent founder events from a few asexually reproducing genotypes. Most geographical and temporal variation observed in the genetic composition resulted from fluctuations of a few predominant clones. In addition, comparisons of the genotypes found in Chile with those described in earlier surveys of $S$. avenae populations in Western Europe led us to identify 'superclones' with large geographical distribution and high ecological success, and to make a preliminary exploration of the putative origin(s) of $S$. avenae individuals introduced to Chile.

Heredity (2005) 95, 24-33. doi:10.1038/sj.hdy.6800662

Published online 20 April 2005

Keywords: Sitobion avenae; microsatellites; genetic variability; introduced species; parthenogenesis

\section{Introduction}

Despite the severe ecological and economic damage caused by introduced species, the genetic and biological properties that allow invaders to become successful in a new niche have not been extensively addressed (Tsutsui et al, 2000, 2001; Sakai et al, 2001). Introduced species that quickly colonize extensive areas offer a good opportunity to decipher the mechanisms that can lead to short-term evolutionary changes, whether stochastic or deterministic, and might eventually lead to speciation. Population bottlenecks following introduction, and genetic drift in small founding populations, can strongly reduce genetic diversity. The mode of reproduction of the introduced organism plays also an important role in modulating these genetic effects (Lynch, 1984; Simon et al, 1999a). Surprisingly, patterns of genetic variation within introduced populations of parthenogenetic species have not been extensively studied (but see Nicol et al, 1997, 1998; Downie, 2002 for aphids). Genetic markers, particularly highly polymorphic ones, have proven useful to identify the genetic source of introduced populations and to document the temporal and spatial dynamics of recent invasions through characterization of their genetic

Correspondence: CC Figueroa, Instituto de Ecología y Evolución, Universidad Austral de Chile, Campus Isla Teja. Casilla 567, Valdivia, Chile. E-mail: christianfigueroa@uach.cl

Received 29 June 2004; accepted 31 January 2005; published online 20 April 2005 structure (Davies et al, 1999). In addition, they provide the genetic background to design new strategies to control introduced pest species.

Aphids show a variety of reproductive modes, from cyclical to obligate (apomictic) parthenogenesis (Moran, 1992; Simon et al, 2002, 2003). In cyclical parthenogenetic (sexual) lineages, asexual multiplication alternates with the production of sexual forms, which mate and lay diapausing eggs resistant to frost. Conversely, obligately parthenogenetic (asexual) lineages continue to reproduce parthenogenetically all year round. However, because they do not produce resistant forms, they play a risky strategy that is only favoured in areas with mild winter (Rispe et al, 1998). In between, intermediate lineages are able simultaneously to overwinter as parthenogenetic individuals while also investing in the sexual production of frost-resistant eggs, that is, they adopt a 'bet-hedging' strategy that is favoured in regions with unpredictable winter climates (Dedryver et al, 1998; Halkett et al, 2004). This ecological link between sexual reproduction and cold resistance is thus expected to result in climatic clines: sexual lineages predominating in cold regions, which are replaced by asexual lineages where winters are mild and by intermediate ones where winter climate fluctuates. This picture is supported by empirical studies that show clines in aphid reproductive mode in spite of strong dispersal and gene flow (Simon et al, 1999a, Dedryver et al, 2001). Additionally, since host specialization is a common feature in aphids (Dixon, 1998), genetic differentiation according to the host plant and the existence of biotypes 
specifically adapted to some host species have been reported in several aphid taxa (Vanlerberghe-Masutti and Chavigny, 1998; Via, 1991, 1999; Downie, 2000; Shufran et al, 2000; Via and Hawthorne, 2002).

In Chile, all cereal aphid species (ie Sitobion avenae (F.), $S$. fragariae (W.), Rhopalosiphum padi (L.), Schizaphis graminum (R.), Diuraphis noxia (K.), Metopolophium dirhodum (W.) and M. festucae cerealium (S.)) have been introduced and all apparently reproduce primarily through obligate parthenogenesis (Fuentes-Contreras et al, 1997). Since introduction, these aphids have caused severe damage to crops through invasion of both cultivated and wild Poaceae such as wheat, oat, barley, maize, cocksfoot grass and wild Hordeum, across a wide geographic zone covering CentralSouthern Chile (Apablaza, 1974; Remaudière et al, 1993; Starý et al, 1994; Fuentes-Contreras et al, 1997).

S. avenae was introduced in Chile some 30 years ago (Apablaza, 1974), and has caused severe crop losses. This aphid is a nonhost-alternating species that lives on numerous species of Poaceae, including cereals and some pasture grasses of temperate climates. It is thought to originate from Europe and the Mediterranean zone but is now distributed worldwide (Blackman and Eastop, 1984). In Western Europe, S. avenae displays the full array of reproductive strategies described above, including sexual, intermediate and asexual lineages (Dedryver et al, 1998; Simon et al, 1999a; Dedryver et al, 2001).

Previous work on the genetic structure of a restricted sample of $S$. avenae in Chile using mainly RAPD-PCR markers showed a low genetic diversity and a lack of host-based genetic structure (Figueroa et al, 1999, 2002). In contrast, in European countries (eg France, UK and Romania), a high genetic variability and genetic differentiation according to the mode of reproduction and the host plant were found using microsatellite loci (De Barro et al, 1995; Sunnucks et al, 1997; Simon et al, 1999a; Llewellyn et al, 2003; Papura et al, 2003).
In this work, we examined the genetic diversity of $S$. avenae in Chile with microsatellites, considering the impact of reproductive mode, interaction with host plants and recent introduction on aphid population structure. The survey included individuals sampled mostly from wheat and oats along a $950 \mathrm{~km}$ latitudinal transect in Central-Southern Chile over 4 years. Additionally, we compared the identity of the genotypes found in Chile with that of clones that have been monitored in earlier surveys of $S$. avenae populations in Western Europe. This attempted (1) to detect clones with large geographical distribution and high ecological success and (2) to tentatively explore the putative origin(s) of $S$. avenae introduced to Chile.

\section{Materials and methods}

\section{Aphid collection}

Sitobion aphids $(N=1749)$ were collected over 4 years on available host plants where they were present at the time and site of collections (Figure 1). Aphids were sampled along a $950 \mathrm{~km}$ latitudinal transect across two agroclimatic zones. Valleys in central Chile with a predominant dry Mediterranean climate constitute zone 1 (Figure 1), while valleys in south-central Chile with a predominant rainy temperate climate constitute zone 2 (Novoa et al, 1989). Zone 1 was sampled in each of the 4 years while zone 2 was sampled only in 1997 and 2000. Six different host plants were sampled: wheat (Triticum durum L), oat (Avena sativa L), cocksfoot grass (Dactylis glomerata L), wild oat (Avena fatua L), mouse barley (Hordeum murinum L), and common velvetgrass (Holcus lanatus L). To limit the chance of sampling individuals from the same colony, each individual aphid was collected from a single host plant separated by at least $10 \mathrm{~m}$ from the next sample.
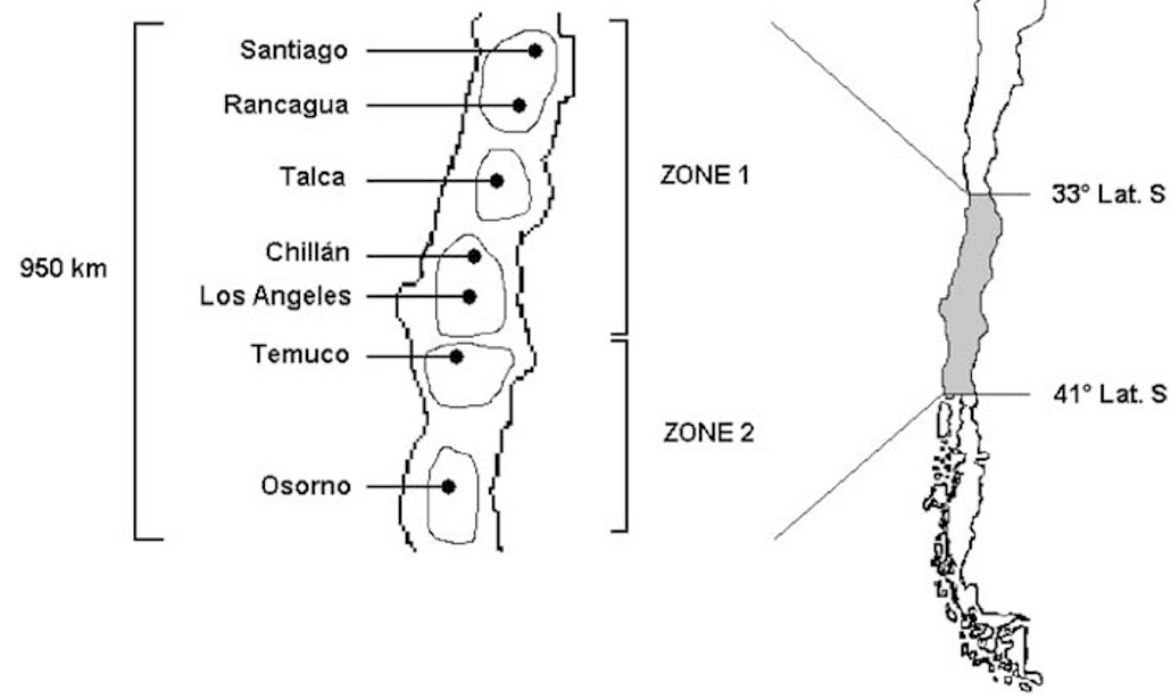

Figure 1 Schematic representation of the two main geographic zones in the latitudinal transect sampled: Zone 1: Central Chile (Santiago, Rancagua, Talca, Chillán and Los Angeles); Zone 2: South-central Chile (Temuco and Osorno). 
All the samples were collected in 95\% ethanol and preserved at $-20^{\circ} \mathrm{C}$ prior to their utilization. Under these conditions, DNA was obtained, which remained of good quality after several months or years of preservation.

As $S$. avenae co-occurs in Chile with its closely related species $S$. fragariae, Sitobion individuals were determined as S. avenae or S. fragariae according to morphological and molecular criteria (Figueroa et al, 1999). As there is evidence for hybridization/introgression between these two Sitobion species, diagnostic alleles from loci Sm10, Sm11 and Sm17 were also used to discriminate between parental species and their putative hybrids (Sunnucks et al, 1997).

\section{Microsatellite loci}

Patterns of allelic diversity in Chilean populations of $S$. avenae were examined at five microsatellite loci. Loci Sm10, Sm11 and Sm17 were isolated from S. miscanthi (Sunnucks et al, 1996), while loci S3.R and S5.L were isolated from S. avenae (Simon et al, 1999a; Wilson et al, 2004). Sm11 is an X-linked locus, while the other loci are autosomal (Wilson et al, 1997; A. Wilson, personal communication). Common genotypes were analysed at six additional microsatellite loci (Sm12, R5.10, S16b, S17b, S3.43 and S30 - Sunnucks et al, 1996; Simon et al, 2001; Wilson et al, 2004) in order to (i) assess whether individuals with identical genotypes at the initial five loci also matched at these additional loci, which would indicate that they were of clonal origin, and (ii) to compare the identity of common Chilean genotypes of $S$. avenae with that of their western Europe counterparts (see below).

Genomic DNA was extracted from wingless adult aphids according to Sunnucks and Hales (1996), and resuspended in $20-40 \mu \mathrm{l}$ of sterile ultrapure water depending on the aphid size.

The PCR amplifications of microsatellite loci were prepared in a $15 \mu \mathrm{l}$ reaction volume, including $0.5 \mathrm{U}$ of Taq DNA polymerase (Invitrogen, USA), $10 \times \mathrm{Mg}^{2+}$ free reaction buffer, $2 \mathrm{mM} \mathrm{MgCl}, 200 \mu \mathrm{M}$ dNTPs, 10 pmol of each primer (BiosChile-IGSA, Chile), and about $10 \mathrm{ng}$ of aphid DNA. The PCR reactions were carried out in a Perkin-Elmer 9700 thermocycler using the following steps: an initial denaturation for $2 \mathrm{~min}$ at $94^{\circ} \mathrm{C}$, and 40 cycles consisting of denaturation for $40 \mathrm{~s}$ at $94^{\circ} \mathrm{C}$, annealing for $45 \mathrm{~s}$ with temperature depending on locus and elongation at $72{ }^{\circ} \mathrm{C}$ for $45 \mathrm{~s}$. For the last cycle, the elongation time was extended to $4 \mathrm{~min}$.

\section{Electrophoresis and silver staining}

The PCR reaction was mixed with $4 \times$ loading buffer (Sambrook et al, 1989), denatured for $3 \mathrm{~min}$ at $95^{\circ} \mathrm{C}$, loaded on a $6 \%$ polyacrylamide-urea gel and subjected to electrophoresis in $0.5 \times \mathrm{TBE}$ at $1.0 \mathrm{kV}$. After electrophoresis, the gel was silver stained as follows. In brief, the gel was fixed in $10 \%$ ethanol, oxidized in $1 \%$ nitric acid, washed with ultrapure water and incubated for $20 \mathrm{~min}$ in a solution of silver nitrate $(1 \mathrm{~g} / \mathrm{l})$. After incubation, the gel was washed and developed in a sodium carbonate/formaldehyde solution (30 g/1 $\mathrm{Na}_{2} \mathrm{CO}_{3}$ and $540 \mu \mathrm{l} / 1$ of $37 \%$ formaldehyde). The reaction was stopped with $10 \%$ acetic acid and the gel washed with water and air-dried at room temperature overnight. The size of the alleles of each locus was estimated using a sequencing size ladder corresponding to the sequence of pGEM $^{\circledR}-3 Z f(+)$ vector (Promega, USA).

\section{Data analysis}

Genetic diversity was evaluated using two indices as in Llewellyn et al (2003). First, the gross genotypic diversity (GGD) was calculated as $G / N$, where $G$ is the number of different multilocus genotypes and $N$ is the sample size. Second, the Shannon-Weaver diversity index $(H)$ was calculated as $H=-\sum_{i} p_{i} \log _{\mathrm{e}} p_{i}$, where $p_{i}$ is the relative frequency of the $i$ th genotype (Shannon and Weaver, 1949). This algorithm determines the genetic diversity in relation to the number of genotypes and their relative abundance in each population. This value can be expressed as $e^{H}$ to obtain an index proportional to the actual number of genotypes found in each population.

Allelic frequencies were calculated using POPULATION software version 1.2.01 (available at http:// www.cnrs-gif.fr/pge/bioinfo). Departures from HardyWeinberg equilibrium (HWE), linkage disequilibrium (LD) and genetic heterogeneity among the entire set or pairwise population samples were analysed using exact tests available in the Genepop package v. 3.2a (Raymond and Rousset, 1995). Significance of multiple pairwise comparisons was tested using Fisher's method (Genepop package). F-statistics were computed according to Weir and Cockerham (1984) using the same software, with bootstrapping according to Weir (1990). The effects of the host plant, zone and year of collection (as well as their interactions) on the distribution of the four most common genotypes (representing ca $90 \%$ of the total sample, see Results below) were analysed using generalized models assuming a binomial error and a logit link function (Mc Cullagh and Nelder, 1989) and performed with S-plus ${ }^{\mathbb{R}}$ statistical software (MathSoft, Cambridge, MA, USA) (Venables and Ripley, 1997). Due to plant availability and sampling constraints, sizes of aphid samples from the various host plants were extremely unbalanced. For that reason, only wheat and oat, on which $S$. avenae individuals were frequently sampled, were considered in the frequency distribution analysis. To investigate the genetic relatedness among Chilean multilocus genotypes, Goldstein's distances (a distance specifically developed for microsatellites, Goldstein et al, 1995) between individual genotypes were calculated with the POPULATION software and a Neighbourjoining tree was subsequently built.

The genotypic features of Chilean individuals were compared with those of French ones. This was achieved using data obtained on French $S$. avenae by Haack et al (2000), who had scored the same set of microsatellites, with the exception of locus S3.R. A subset (200 individuals) of the sample of Haack et al (2000) was therefore analysed for variation at S3.R for a full comparison with Chilean genotypes. After this additional genotyping, 56 five-locus genotypes were discriminated within this subset of French $S$. avenae and retained for comparison with Chilean genotypes.

\section{Results}

\section{Occurrence of $\mathrm{S}$. avenae and $\mathrm{S}$. fragariae}

Of the 1749 individuals analysed, 1052 were S. avenae (exhibiting diagnostic alleles exclusive to S. avenae), 640 
were S. fragariae (exhibiting diagnostic alleles exclusive to $S$. fragariae), and 57 were considered as putative hybrids (sharing alleles from S. avenae and S. fragariae). Genetic data on $S$. fragariae and putative $S a \times S f$ hybrids are not presented in this paper, as they will be published elsewhere. S. avenae was mainly found on cultivated cereals $(89.1 \%)$, but it was also present on wild grasses (with the exception of velvet grass) and particularly on cocksfoot grass (Table 1). On the other hand, $S$. fragariae preferentially occurred on wild pastures (57.3\%), and it coexisted locally with $S$. avenae (data not shown).

\section{Genetic diversity and within population structure revealed by microsatellite loci}

Only 44 multilocus genotypes were distinguished within the whole sample of $S$. avenae individuals $(N=1052)$. Their allelic combination at each locus is indicated in Table 2. Genetic diversity, as measured by the GGD and Shannon-Weaver indices, was very low (Table 3). Overall, only $4 \%$ of the collections of Chilean S. avenae consisted of unique genotypes while the four most common ones (Sa1: 378 copies, Sa2: 340 copies, Sa3: 127 copies, and Sa4: 75 copies) represented over $87 \%$ of the sample (Table 3). Furthermore, the examination of several copies (from 4 to 10) for each of the eight most common genotypes at six additional microsatellite loci did not lead to the discrimination of further multilocus genotypes, suggesting that most genotypic diversity was resolved with the first five loci (data not shown).

An analysis of genotype proportions was carried out considering only a single copy of each of the 44 multilocus genotypes, so the results did not simply reflect the differential clonal amplification of the genotypes. Frequent deviations from the HW genetic equilibrium were detected at all loci (Table 4). The deviations were attributable to significant heterozygote excess at loci Sm11, S5.L, Sm17 and strong heterozygote deficit at locus S3.R (Table 4). Although failures in PCR reactions were not particularly observed at this locus, which would have been suggestive of homozygous null individuals, the possibility of null alleles cannot be completely excluded. No LD was detected among the microsatellite loci studied considering only the 44 genotypes.

\section{Distribution of multilocus genotypes according to host plant, year and zone}

The effect of year (1996, 1997, 2000), zone (zones 1 and 2) and plant (oat and wheat) of aphid collection was studied on the frequency distribution of each of the four most common genotypes (those representing ca $90 \%$ of the total sample).

Genotype Sa1 showed highly significant changes in frequency across years: while nearly absent before 1999 , it was by far the most abundant genotype in 2000 (Table 3). In addition, Sa1 was significantly more frequent in zone 1 and on wheat, these two last factors being independent (Table 5). Genotype Sa2 also varied in frequency between years: being predominant in 1996, it showed a slight but significant decrease until 2000 (Table 3). Globally, Sa2 was more frequent on wheat than oat but the significant plant-year interaction indicated this was not true for all years (Table 5). Genotype Sa3 varied in frequency only between years (see Tables 3 and 5). Finally, year, plant and plant-year interaction influenced significantly the frequency distribution of Sa4. This genotype was frequent in 1997 but showed an abrupt decline in frequency the following years (Table 3). Globally, Sa4 was more common on oat than wheat, but this also depended on years as indicated by the significant plant-year interaction (Table 5).

Relatedness among Chilean multilocus genotypes of $S$. avenae and comparison with their French counterparts The microsatellite tree (based on five loci) separated the 44 multilocus genotypes of $S$. avenae found in Chile into three main types (Figure 2). Group 1 gathered 28 genotypes $(64 \%)$ that shared many alleles of closely related size. It is noteworthy that group 1 included three of the four most common clones, notably Sa1 and Sa2, which differed by a single allele at locus S5.L (Table 2). Similarly, group 2 included 10 highly related genotypes (23\%) among them being Sa3, the third most common clone. The remaining six genotypes (13\%) branched individually on the tree and were remote from each other and from groups 1 and 2 by long branches. The two main groups differed from each other by 10 allelic changes on average. For instance, Sa3 (group 2) differed from Sa1 (group 1) by 11 changes and from Sa2 and Sa4 (group 1) by 8-10 changes (Table 2).

The comparison of allelic frequencies at the five microsatellite loci between Chilean and French populations showed in Chilean genotypes a $34 \%$ reduction in allelic diversity as compared with French genotypes (19 and 28 alleles at the five loci for Chilean and French genotypes, respectively). Most alleles found in Chilean populations of S. avenae (ca 80\%) were also found in French populations with only four alleles (S3.R $R^{338}$, $S m 17^{181}, S m 10^{163}$ and $S m 10^{165}$ ) restricted to Chile. Apart from $S 5 . L^{223}$, the most frequent alleles in Chilean

Table 1 Distribution and abundance of Sitobion avenae in Chile according to the host plant, year of collection and agroclimatic zone

\begin{tabular}{|c|c|c|c|c|c|c|c|}
\hline \multirow[t]{2}{*}{ Host plant } & \multicolumn{4}{|c|}{ Zone 1} & \multicolumn{2}{|c|}{ Zone 2} & \multirow[t]{2}{*}{ Total } \\
\hline & 1996 & 1997 & 1999 & 2000 & 1997 & 2000 & \\
\hline Wheat & 28 & 65 & 62 & 440 & 42 & 125 & 762 \\
\hline Oat & 35 & 21 & ND & 77 & 24 & 18 & 175 \\
\hline Cocksfoot grass & 1 & 45 & ND & 4 & 13 & 7 & 70 \\
\hline Wild-oat & 10 & ND & ND & 8 & ND & 9 & 27 \\
\hline Mouse barley & ND & ND & 6 & 10 & ND & 2 & 18 \\
\hline Total & 74 & 131 & 68 & 539 & 79 & 161 & 1052 \\
\hline
\end{tabular}

ND: Not detected. 
Table 2 Allelic combinations of the 44 multilocus genotypes of Sitobion avenae characterized in Chile

\begin{tabular}{|c|c|c|c|c|c|}
\hline \multirow[t]{2}{*}{ Genotype } & \multicolumn{5}{|c|}{ Microsatellite locus } \\
\hline & S3.R & $\operatorname{Sm} 11$ & S5.L & $\operatorname{Sm17}$ & $\operatorname{Sm} 10$ \\
\hline Sa1 & $337 / 337$ & $144 / 149$ & $225 / 227$ & $178 / 179$ & $164 / 166$ \\
\hline $\mathrm{Sa} 2$ & $337 / 337$ & $144 / 149$ & $223 / 227$ & $178 / 179$ & $164 / 166$ \\
\hline Sa3 & $361 / 361$ & $144 / 149$ & $223 / 227$ & $178 / 179$ & $164 / 166$ \\
\hline Sa4 & $337 / 337$ & $144 / 149$ & $223 / 227$ & $178 / 179$ & $164 / 164$ \\
\hline Sa5 & $337 / 337$ & $144 / 149$ & $223 / 227$ & $177 / 179$ & $164 / 166$ \\
\hline Sa6 & $337 / 361$ & $144 / 149$ & $225 / 227$ & $178 / 179$ & $166 / 166$ \\
\hline Sa7 & $361 / 361$ & $144 / 149$ & $223 / 227$ & $178 / 179$ & $164 / 164$ \\
\hline Sa8 & $337 / 337$ & $144 / 149$ & $223 / 227$ & $177 / 178$ & $164 / 166$ \\
\hline Sa9 & $337 / 337$ & $144 / 149$ & $225 / 227$ & $177 / 179$ & $164 / 166$ \\
\hline Sa10 & $337 / 337$ & $144 / 144$ & $223 / 227$ & $178 / 179$ & $164 / 166$ \\
\hline Sa11 & $361 / 361$ & $144 / 149$ & $223 / 227$ & $177 / 179$ & $164 / 166$ \\
\hline Sa12 & $337 / 337$ & $144 / 149$ & $225 / 227$ & $178 / 179$ & $166 / 166$ \\
\hline Sa13 & $337 / 337$ & $144 / 149$ & $223 / 227$ & $178 / 179$ & $166 / 166$ \\
\hline Sa14 & $337 / 337$ & $149 / 149$ & $223 / 227$ & $178 / 179$ & $164 / 164$ \\
\hline Sa15 & $337 / 337$ & $144 / 149$ & $227 / 227$ & $178 / 179$ & $166 / 168$ \\
\hline Sa16 & $337 / 337$ & $149 / 149$ & $223 / 227$ & $178 / 179$ & $164 / 166$ \\
\hline Sa17 & $337 / 361$ & $149 / 149$ & $225 / 227$ & $178 / 179$ & $166 / 166$ \\
\hline Sa18 & $361 / 361$ & $144 / 149$ & $223 / 227$ & $177 / 178$ & $164 / 166$ \\
\hline Sa19 & $337 / 337$ & $144 / 149$ & $223 / 227$ & $178 / 179$ & $166 / 168$ \\
\hline Sa20 & $337 / 361$ & $144 / 149$ & $223 / 227$ & $178 / 179$ & $164 / 166$ \\
\hline Sa21 & $337 / 361$ & $144 / 149$ & $227 / 227$ & $178 / 179$ & $164 / 164$ \\
\hline Sa22 & $337 / 337$ & $149 / 149$ & $223 / 227$ & $178 / 179$ & $166 / 168$ \\
\hline Sa23 & $337 / 337$ & $143 / 143$ & $223 / 227$ & $178 / 179$ & $164 / 164$ \\
\hline $\mathrm{Sa} 24$ & $337 / 337$ & $143 / 148$ & $223 / 227$ & $178 / 179$ & $164 / 164$ \\
\hline Sa25 & $361 / 361$ & $144 / 144$ & $223 / 227$ & $178 / 179$ & $166 / 166$ \\
\hline Sa26 & $337 / 337$ & $144 / 149$ & $223 / 227$ & $177 / 177$ & $164 / 164$ \\
\hline Sa27 & $337 / 337$ & $144 / 149$ & $223 / 227$ & $177 / 177$ & $164 / 166$ \\
\hline Sa28 & $361 / 361$ & $144 / 149$ & $223 / 227$ & $177 / 179$ & $166 / 168$ \\
\hline Sa29 & $338 / 338$ & $144 / 149$ & $223 / 227$ & $178 / 179$ & $164 / 166$ \\
\hline Sa30 & $338 / 338$ & $144 / 149$ & $223 / 227$ & $178 / 179$ & $166 / 166$ \\
\hline Sa31 & $337 / 337$ & $144 / 149$ & $223 / 227$ & $178 / 179$ & $163 / 164$ \\
\hline Sa32 & $337 / 361$ & $144 / 149$ & $223 / 227$ & $178 / 179$ & $164 / 164$ \\
\hline Sa33 & $337 / 337$ & $144 / 149$ & $223 / 227$ & $179 / 181$ & $164 / 166$ \\
\hline Sa34 & $337 / 337$ & $144 / 149$ & $225 / 227$ & $178 / 179$ & $163 / 165$ \\
\hline Sa35 & $337 / 337$ & $144 / 149$ & $225 / 227$ & $178 / 179$ & $163 / 166$ \\
\hline Sa36 & $337 / 337$ & $144 / 149$ & $225 / 227$ & $178 / 179$ & $164 / 164$ \\
\hline Sa37 & $337 / 337$ & $144 / 149$ & $225 / 227$ & $178 / 179$ & $166 / 168$ \\
\hline Sa38 & $361 / 361$ & $144 / 149$ & $225 / 227$ & $178 / 179$ & $164 / 166$ \\
\hline Sa39 & $337 / 361$ & $144 / 149$ & $227 / 227$ & $178 / 179$ & $164 / 166$ \\
\hline Sa40 & $337 / 337$ & $148 / 149$ & $223 / 227$ & $178 / 179$ & $164 / 164$ \\
\hline Sa41 & $361 / 361$ & $149 / 149$ & $223 / 227$ & $178 / 179$ & $164 / 164$ \\
\hline Sa42 & $361 / 361$ & $149 / 149$ & $223 / 227$ & $178 / 179$ & $164 / 166$ \\
\hline Sa43 & $337 / 337$ & $149 / 149$ & $225 / 227$ & $178 / 179$ & $164 / 164$ \\
\hline Sa44 & $361 / 361$ & $149 / 149$ & $227 / 227$ & $177 / 179$ & $164 / 166$ \\
\hline
\end{tabular}

Table 3 Multilocus genotypes of Sitobion avenae identified along all collection zones and years. The number of individuals collected per genotype is indicated for each sampling unit

\begin{tabular}{|c|c|c|c|c|c|c|c|c|c|c|c|c|}
\hline \multirow[t]{2}{*}{ Genotype } & \multicolumn{3}{|c|}{ Host plant } & \multicolumn{4}{|c|}{ Zone 1} & \multicolumn{2}{|c|}{ Zone 2} & \multirow[t]{2}{*}{ Total } & \multirow[t]{2}{*}{ Frequency } & \multirow[t]{2}{*}{ Cumulated frequency } \\
\hline & Wheat & Oat & Other & 1996 & 1997 & 1999 & 2000 & 1997 & 2000 & & & \\
\hline Sa1 & 346 & 21 & 11 & 0 & 0 & 48 & 309 & 0 & 21 & 378 & 0.359 & 0.359 \\
\hline $\mathrm{Sa} 2$ & 207 & 79 & 53 & 43 & 59 & 6 & 136 & 45 & 51 & 340 & 0.323 & 0.682 \\
\hline $\mathrm{Sa} 3$ & 89 & 23 & 15 & 8 & 2 & 11 & 79 & 1 & 26 & 127 & 0.121 & 0.803 \\
\hline Sa4 & 29 & 30 & 16 & 11 & 37 & 1 & 5 & 21 & 0 & 75 & 0.071 & 0.874 \\
\hline Sa5 & 21 & 1 & 0 & 0 & 0 & 0 & 0 & 0 & 22 & 22 & 0.021 & 0.895 \\
\hline Sa6 & 7 & 2 & 7 & 2 & 14 & 0 & 0 & 0 & 0 & 16 & 0.015 & 0.910 \\
\hline Sa7 & 4 & 8 & 2 & 1 & 9 & 1 & 0 & 3 & 0 & 14 & 0.013 & 0.923 \\
\hline Sa8 & 7 & 2 & 0 & 0 & 0 & 0 & 1 & 0 & 8 & 9 & 0.009 & 0.932 \\
\hline Sa9-Sa44 & 52 & 9 & 10 & 7 & 8 & 0 & 14 & 8 & 34 & 71 & 0.068 & 1.000 \\
\hline Total & 762 & 175 & 115 & 72 & 129 & 67 & 544 & 78 & 162 & 1052 & & \\
\hline Genotype number & 34 & 15 & 16 & 12 & 12 & 6 & 10 & 10 & 19 & 44 & & \\
\hline GGD & 0.04 & 0.09 & 0.14 & 0.17 & 0.09 & 0.09 & 0.02 & 0.13 & 0.12 & 0.04 & & \\
\hline$e^{\mathrm{H}}$ & 5.42 & 5.38 & 6.08 & 4.37 & 4.66 & 2.56 & 2.99 & 3.66 & 8.59 & 6.21 & & \\
\hline
\end{tabular}

GGD = gross genotypic diversity; $e^{H}=$ Shannon-Weaver genotypic diversity. 
Table 4 Observed heterozygosities, exact test for the homogeneity of genotypic frequencies with respect to HW equilibrium, and F-statistics for the microsatellite loci studied in the 44 Chilean genotypes of Sitobion avenae

\begin{tabular}{lcrcc}
\hline Locus & $\begin{array}{c}\text { Observed } \\
\text { heterozygosity }\end{array}$ & $\mathrm{F}_{I S}$ & $\begin{array}{c}\text { Heterozygote } \\
\text { excess } \\
\text { (P-value) }\end{array}$ & $\begin{array}{c}\text { Heterozygote } \\
\text { deficit } \\
\text { (P-value) }\end{array}$ \\
\hline S3.R & 0.136 & 0.719 & 1.000 & $<0.001$ \\
Sm11 & 0.750 & -0.372 & 0.846 & 0.154 \\
S5.L & 0.909 & -0.564 & $<0.001$ & 1.000 \\
Sm17 & 0.956 & -0.556 & $<0.001$ & 0.999 \\
Sm10 & 0.591 & 0.009 & 0.443 & 0.601 \\
Multilocus & 0.668 & -0.184 & 0.786 & 0.234 \\
\hline
\end{tabular}

Table 5 Frequency distribution analysis of the most common multilocus genotypes of Sitobion avenae considering the interaction between year and zone of collection, and the host plant

\begin{tabular}{lcccl}
\hline Multilocus genotype & Year & Zone & Plant & Interactions \\
\hline Sa1 & $* *$ & $* *$ & $* *$ & NS \\
Sa2 & $* *$ & NS & $*$ & Plant-year $(* *)$ \\
Sa3 & $* *$ & NS & NS & NS \\
Sa4 & $* *$ & NS & $* *$ & Plant-year $(* *)$ \\
\hline
\end{tabular}

${ }^{*} P<0.05 ;{ }^{* *} P<0.005 ; \mathrm{NS}=$ nonsignificant. genotypes were also the most common in France at each of the five microsatellite loci.

Comparing microsatellite profiles of the most common genotypes in the two countries at 11 loci showed that Sa1 shares exactly the same 11-locus genotype with G6, the third most common clone in the French sample studied by Haack et al (2000), indicating they derive from the same clone (Table 6). When the four loci in common with other genotypic surveys of $S$. avenae and the present study were considered (Sm10,Sm11, Sm12 and Sm17), none of the four most common Chilean clones had a multilocus profile matching exactly that of either British (Sunnucks et al, 1997; Llewellyn et al, 2003, 2004) or other French (Simon et al, 1999a) genotypes.

\section{Discussion}

Chilean populations of $S$. avenae encompass a few heterozygous multilocus genotypes

In contrast to reports for European populations (Sunnucks et al, 1997; Simon et al, 1999a; Haack et al, 2000; Llewellyn et al, 2003, 2004; Papura et al, 2003), S. avenae populations in Chile showed a very low clonal diversity, independent of the host plant, geographic zone, or sampling season. As compared with the $4 \%$ of genotypic

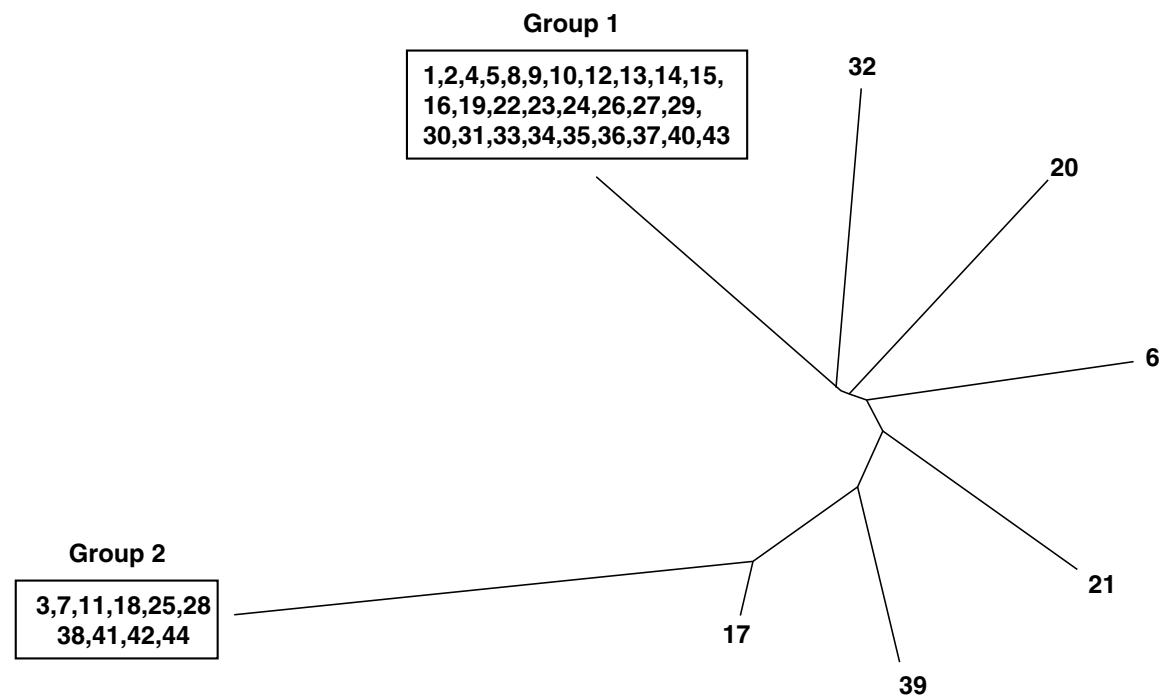

Figure 2 Neighbour-joining tree based on Goldstein's distance (Goldstein et al, 1995) calculated with five microsatellite loci for the 44 multilocus genotypes discriminated in Chilean populations of Sitobion avenae.

Table 6 Comparison between some of the most common genotypes of Sitobion avenae in Chile and France at 11 microsatellite loci

\begin{tabular}{|c|c|c|c|c|c|c|c|c|c|c|c|}
\hline \multirow[t]{2}{*}{ Genotypes } & \multicolumn{11}{|c|}{ Microsatellite locus } \\
\hline & $\operatorname{Sm} 10$ & $\operatorname{Sm} 11$ & $\operatorname{Sm} 17$ & Sm12 & S5.L & $S 3 . R$ & R5.10 & $S 16 b$ & $S 17 b$ & S3.43 & S30 \\
\hline \multicolumn{12}{|l|}{ In Chile } \\
\hline Sa1 & $164 / 166$ & $144 / 149$ & $178 / 179$ & $169 / 169$ & $225 / 227$ & $337 / 337$ & $272 / 272$ & $162 / 176$ & 199/199 & $185 / 185$ & $164 / 164$ \\
\hline Sa2 & $164 / 166$ & $144 / 149$ & $178 / 179$ & $151 / 157$ & $223 / 227$ & $337 / 337$ & $268 / 272$ & 190/190 & $215 / 217$ & $185 / 193$ & $164 / 166$ \\
\hline Sa3 & $164 / 166$ & $144 / 149$ & $178 / 179$ & $139 / 151$ & $223 / 227$ & $361 / 361$ & $272 / 272$ & $210 / 214$ & $205 / 209$ & $185 / 193$ & $164 / 166$ \\
\hline Sa4 & $164 / 164$ & $144 / 149$ & $178 / 179$ & $151 / 165$ & $223 / 227$ & $337 / 337$ & $268 / 272$ & $190 / 190$ & $215 / 217$ & $185 / 193$ & $164 / 166$ \\
\hline \multicolumn{12}{|l|}{ In France } \\
\hline G2 & $164 / 166$ & $144 / 149$ & $178 / 179$ & $165 / 165$ & $225 / 227$ & $345 / 361$ & $268 / 272$ & $150 / 206$ & $199 / 205$ & $185 / 185$ & $164 / 166$ \\
\hline G5 & $164 / 166$ & $144 / 148$ & $178 / 179$ & $151 / 151$ & $223 / 225$ & $337 / 337$ & $272 / 272$ & $162 / 176$ & $199 / 217$ & $185 / 186$ & $164 / 166$ \\
\hline G6 & $164 / 166$ & $144 / 149$ & $178 / 179$ & $169 / 169$ & $225 / 227$ & $337 / 337$ & $272 / 272$ & $162 / 176$ & 199/199 & $185 / 185$ & $164 / 164$ \\
\hline
\end{tabular}


diversity found in this work, Haack et al (2000) and Llewellyn et al (2003) have reported 26 and $46 \%$ of genotypic diversity (obtained with the same number of microsatellite markers), in French and British populations, respectively: about 10-fold more genotypic diversity than in this apparently asexual population (see below) of $S$. avenae in Chile. This low genetic diversity in Chilean populations could be the result both of their recent introduction (Apablaza, 1974) through founder effects, and/or of their absence or rarity of sexual reproduction among Chilean populations, as already proposed for other Sitobion species introduced to Australia (Sunnucks et al, 1996; Wilson et al, 1999).

The low genetic diversity of $S$. avenae in Chile was accompanied by an extremely high level of heterozygosity ( $>99 \%$ at some loci), which could have three complementary explanations. Firstly, the genotypes that became established may have been continuously parthenogenetic since their introduction because of the mild climate prevalent in areas where cereal crops are cultivated in Chile. After many rounds of parthenogenetic generations, $S$. avenae populations in Chile could have accumulated high levels of heterozygosity through allelic divergence at neutral nuclear loci, as previously proposed for other asexual lineages of aphids (for Rhopalosiphum padi see Simon et al, 1999b; Delmotte et al, 2001, 2002; for Myzus persicae see Vorburger et al, 2003; for S. avenae and other related species see Wilson et al, 1999, 2003; Papura et al, 2003). Alternatively, it has been found recently that asexual lineages of aphids can arise from hybridization: either between two distinct parental species or between differentiated lineages of the same species (Delmotte et al, 2002, 2003; Simon et al, 2003). S. avenae genotypes introduced to Chile could have such hybrid origin(s) that arose in their source populations that would readily explain their high heterozygosity. Finally, an array of genotypes with varying heterozygosity could have been introduced to Chile and selection then favoured heterozygous combinations due to heterosis or associative overdominance. The discrimination between these three hypotheses requires deeper information on Chilean genotypes obtained at allele sequence level along with heterozygosity-fitness correlation assessment.

\section{Predominance of genetically related asexual lineages of} S. avenae in Chile

Reproductive mode variation in aphids is strongly determined by climatic factors because of the existing link between sexual reproduction and the production of eggs resistant to frost (Simon et al, 2002). As a result, cyclically parthenogenetic genotypes tend to be more abundant in areas with cold winter while the opposite seems to apply to obligately parthenogenetic genotypes. Aphids were sampled mainly in valleys of central Chile, where climate is characterized by warm winters with no snowfall (Novoa et al, 1989). These environmental conditions would favour the prevalence of permanent parthenogenesis over cyclical parthenogenesis (Rispe et al, 1998; Dedryver et al, 2001). Since S. avenae populations were characterized by low clonal diversity with a few time-persistent genotypes, and a high heterozygosity for the markers studied, these genetic features provide evidence for a predominance of asexual reproduction in Chile. However, the possibility that some $S$. avenae genotypes have rare events of sexual reproduction in Chile cannot be excluded. Laboratory observations have revealed that some Chilean $S$. avenae genotypes still possess the ability to produce sexual individuals when they are placed at low temperatures and short day conditions (Dedryver et al, unpublished data). This was also the case for Sitobion aphids in Australia that reproduced asexually in the field but retained, at least for some clones, the capability of sexual reproduction in the laboratory (Wilson et al, 1999, 2003). Therefore, if genotypes still capable of sexual reproduction are present in colder regions of Chile (eg higher altitudes, austral territories) than those surveyed here, they may regularly generate recombined genotypes that could migrate and admix with the bulk of asexual clones. A phenotypic assessment of reproductive modes of Chilean genotypes of $S$. avenae is needed to explore in details the possibility of sexual events in Chile.

The analysis of genetic relationships among genotypes revealed two main groups clustering most genotypes (38 out of 44). Since genetic relatedness among genotypes belonging to the same group is very high, and assuming that obligate parthenogenesis is the primary mode of reproduction, this pattern suggests that groups 1 and 2 represent two different origins of introduction followed by genotypic diversification through mutation (Wilson et al, 2003). For example, in group 1, genotype Sa2 differed from Sa4 by only two alleles $\left(S m 10^{166}\right.$ and $S m 12^{157}$ ) out of 22 , strongly suggesting that they have diverged through mutations after being introduced to Chile. Clones that were at low frequency at the beginning of the survey (eg Sa5 and Sa8) could have acquired ecological traits (by mutation assuming the absence of recombination) that increased subsequently their fitness leading to an abrupt increase in frequency during the following years (Sunnucks et al, 1998). On the other hand, the remote position of the remaining six genotypes on the tree could be explained in several ways. For instance, they could originate from (i) supplementary introduction events that are continuously occurring from neighbouring or remote countries, (ii) scarce recombination episodes (see above) or (iii) gene flow from plants that have not been sampled in this survey. Alternatively, mutations could be producing new genotypes at a high rate, accounting for those unrelated genotypes, and for those genotypes that suddenly appeared in this 4-year study.

\section{Broad ecological tolerance of common Chilean genotypes} of $S$. avenae and the hypothesis of 'superclones'

Contrasting with previous works reporting host specialization in Sitobion (De Barro et al, 1995; Sunnucks et al, 1997, 1998; Lushai et al, 2002), none of the most common Chilean genotypes was strictly associated with any of the five host plants considered in the present study. This latter observation is in agreement with results obtained in France, where two genotypes of $S$. avenae were mainly found on maize but also occurred on other species of cereals (Haack et al, 2000). However, some Chilean genotypes showed significant differences in their frequency distribution between host plants. This could result from variation in performance and/or preferences among Chilean genotypes of $S$. avenae, some being more 
specialists (eg Sa1, Sa2 and Sa4) and other being more generalist (Sa3) in character. Plant chemical defences such as hydroxamic acids (Niemeyer and Pérez, 1995) have been proposed as modulators of genetic variability in S. avenae populations (Figueroa et al, 2002). Recently, we have shown that the most common genotypes of Chilean $S$. avenae differ in their performance and survival when reared on oat (no defences) and wheat cultivars with different levels of hydroxamic acids (Figueroa et al, 2004). For example, Sa1 performed better on defended plants while Sa2 performed equally on plants with low and high hydroxamic acids. Thus, the extreme abundance of these two genotypes across Chile could be the result of clonal selection promoting the emergence of 'superclones' (Llewellyn et al, 2003; Vorburger et al, 2003), which would be characterized by a broad host range and a low variance in their performances on host plants with different defence chemicals levels. The $100 \%$ of identity at 11 microsatellite loci between the widespread Sa1 (Chilean) and G6 (French) genotypes gives additional support to the existence of 'superclones' in S. avenae. Further work is needed to check whether the Sa1/G6 genotype has an even broader distribution, as observed for a genotype of the aphid Myzus antirrhinii which is distributed across several continents and feeds on a wide range of host plants (Wilson et al, 2003).

\section{Concluding remarks and future directions}

In this paper, we presented the population genetic properties of the introduced aphid pest $S$. avenae in Chile, featured by a markedly low genetic variability, with a few genotypes having low plant preferences. This lack of genetic diversity in Chile is likely to result from the recent introduction of a few asexual genotypes. Some of these introduced genotypes seem to have achieved tremendous ecological success in a short period of time. However, clonal turnover may be very rapid as observed during this 4-year survey.

It is surprising that despite their lack of genetic variation, populations of $S$. avenae were able to successfully colonize different cultivated and wild host plants throughout different agroclimatic zones along hundreds of kilometres in Chile. This paradox of successful introductions of genetically poor invaders is not new. Although reductions in genetic diversity are generally considered detrimental, the Argentine ant, Linepithema humile, constitutes an example of how a genetic bottleneck can precede widespread ecological success when they invade a new niche (Tsutsui et al, 2000, 2001). However, aphids, by their asexual mode of reproduction (either partial or complete), their high dispersal capacities through direct flights or trade exchanges and the existence of 'superclones' seem to be particularly well suited to rapid conquest of new habitats.

Additional work is needed to get a clearer understanding on the origin and dynamics of this introduced pest species, which is also a requirement to design appropriate management strategies. Detailed studies should be conducted to identify the source(s) of populations of $S$. avenae introduced to Chile and to explain the biological and genetic reasons for the ecological success of introduced genotypes. It will also be intriguing to follow the fate of the clones that are currently have wide geographic and ecological ranges into the future, to establish whether there is evidence of an increased role for niche specialization and recombination as evolution proceeds in the novel Chilean environment.

\section{Acknowledgements}

This work was funded by FONDECYT Grants 2000060 and 3020051 to CCF, the Presidential Chair in Sciences awarded to HMN, and ECOS-CONICYT Grant C96B04. We thank JP Gauthier and Y Outreman for helping with statistical analyses, and two anonymous reviewers who provided valuable comments on the manuscript.

\section{References}

Apablaza J (1974). Presencia de Macrosiphum (Sitobion) avenae (F) (Homoptera, Aphididae) en sementeras de trigo en Chile. Cienc Invest Agrar 1: 69-70.

Blackman RL, Eastop VF (1984). Aphids On The World's Crops: An Identification and Information Guide. John Wiley and Sons: Chichester.

Davies N, Villablanca FX, Roderick GK (1999). Determining the source of individuals: multilocus genotyping in nonequilibrium population genetics. Trends Ecol Evol 14: 17-21.

De Barro PJ, Sheratt TN, Brookes CP, David O, Maclean N (1995). Spatial and temporal genetic variation in British field populations of the grain aphid Sitobion avenae (F) (Hemiptera: Aphididae) studied using RAPD-PCR. Proc Roy Soc London B 262: 321-327.

Dedryver A, Hullé M, Le Gallic JF, Caillaud M, Simon JC (2001). Coexistence in space and time of sexual and asexual populations of the cereal aphid Sitobion avenae. Oecologia 128: $379-388$.

Dedryver CA, Le Gallic JF, Gauthier JP, Simon JC (1998). Lifecycle of the cereal aphid Sitobion avenae F: polymorphism and comparison of life-history traits associated with sexuality. Ecol Entomol 23: 123-132.

Delmotte F, Leterme N, Bonhomme J, Rispe C, Simon JC (2001). Multiple routes to asexuality in an aphid species. Proc Roy Soc London B 268: 2291-2299.

Delmotte F, Leterme N, Gauthier JP, Rispe C, Simon JC (2002). Genetic architecture of sexual and asexual populations of the aphid Rhopalosiphum padi based on allozyme and microsatellite markers. Mol Ecol 11: 711-723.

Delmotte F, Sabater B, Leterme N, Latorre A, Sunnucks P, Rispe C et al (2003). Phylogenetic evidence for hybrid origins of asexual lineages in an aphid species. Evolution 57: 1291-1303.

Dixon AFG (1998). Aphid Ecology. Chapman and Hall: London.

Downie DA (2000). Patterns of genetic variation in native grape phylloxera on two sympatric host species. Mol Ecol 9: 505-514.

Downie DA (2002). Locating the sources of an invasive pest, grape phylloxera, using a mitochondrial DNA gene genealogy. Mol Ecol 11: 2013-2026.

Figueroa CC, Loayza-Muro R, Niemeyer HM (2002). Temporal variation of RAPD-PCR phenotype composition of the grain aphid Sitobion avenae (Hemiptera: Aphididae) on wheat: the role of hydroxamic acids. Bull Entomol Res 92: 25-33.

Figueroa CC, Simon JC, Le Gallic JF, Niemeyer HM (1999). Molecular markers to differentiate two morphologicallyclose species of the genus Sitobion (Homoptera: Aphidoidea). Entomol Exp Appl 92: 217-225.

Figueroa CC, Simon JC, Le Gallic JF, Prunier-Leterme N, Briones LM, Dedryver CA et al (2004). Effect of host defence chemicals on clonal distribution and performance of different genotypes of the cereal aphid Sitobion avenae (Hemiptera: Aphididae). J Chem Ecol 30: 2515-2525.

Fuentes-Contreras E, Muñoz R, Niemeyer HM (1997). Diversidad de áfidos (Hemiptera: Aphidoidea) en Chile. Rev Chil Hist Nat 70: 531-542. 
Goldstein DB, Ruíz-Linares A, Feldman M, Cavalli-Sforza LL (1995). An evaluation of genetic distances for use with microsatellite loci. Genetics 139: 463-471.

Haack L, Simon JC, Gauthier JP, Plantegenest M, Dedryver CA (2000). Evidence for predominant clones in a cyclically parthenogenetic organism provided by combined demographic and genetic analysis. Mol Ecol 9: 2055-2066.

Halkett F, Harrington R, Hulle M, Kindlmann P, Menu F, Rispe $C$, et al (2004). Dynamics of production of sexual forms in aphids: theoretical and experimental evidence for adaptive 'coin-flipping' plasticity. Am Nat 163: E112-E125.

Llewellyn KS, Loxdale HD, Harrington R, Brookes CP, Clark SJ, Sunnucks P (2003). Migration and genetic structure of the grain aphid (Sitobion avenae) in Britain related to climate and clonal fluctuation as revealed using microsatellites. Mol Ecol 12: $21-34$

Llewellyn KS, Loxdale HD, Harrington R, Clark SJ, Sunnucks P (2004). Evidence for gene flow and local clonal selection in field populations of the grant aphid (Sitobion avenae) in Britain revealed using microsatellites. Heredity 93: 143-153.

Lushai G, Markovitch O, Loxdale HD (2002). Host-based genotype variation in insects revisited. Bull Entomol Res 92: 159-164.

Lynch M (1984). Destabilizing hybridization, general-purpose genotypes and geographic parthenogenesis. $Q$ Rev Biol 59: 257-290.

Mc Cullagh P, Nelder JA (1989). Generalized Linear Models, 2nd edn. Chapman and Hall: London.

Moran NA (1992). The evolution of aphid life cycles. Annu Rev Entomol 37: 321-348.

Nicol D, Armstrong KF, Wratten SD, Cameron CM, Frampton C, Fenton B (1997). Genetic variation in an introduced aphid pest (Metopolophium dirhodum) in New Zealand and relation to individuals from Europe. Mol Ecol 6: 255-265.

Nicol D, Armstrong KF, Wratten SD, Walsh PJ, Straw NA, Cameron CM et al (1998). Genetic diversity of an introduced pest, the green spruce aphid Elatobium abietinum (Hemiptera: Aphididae) in New Zealand and the United Kingdom. Bull Entomol Res 88: 537-543.

Niemeyer HM, Pérez FJ (1995). Potential of hydroxamic acids in the control of cereal pests, diseases and weeds. In: Inderjit K, Dakshini MM, Einhellig FA (eds) Allelopathy: Organisms, Processes, and Applications ACS Symposium Series American Chemical Society: Washington, DC, pp 260-270.

Novoa R, Villaseca S, del Canto P, Rouanet JL, Sierra C, del Pozo A (1989). Mapa agroclimático de Chile. Instituto de Investigaciones Agropecuarias (INIA): Santiago.

Papura D, Simon JC, Halkett F, Delmotte F, Le Gallic JF, Dedryver CA (2003). Predominance of sexual reproduction in Romanian populations of the aphid Sitobion avenae inferred from phenotypic and genetic structure. Heredity 90: 397-404.

Raymond M, Rousset F (1995). Genepop, a population genetics software for exact tests and oecumenicism. J Hered 86: 248-249.

Remaudière G, Starý P, Gerding M (1993). Sitobion fragariae (Walker) and Metopolophium festucae cerealium Stroyan, two new cereal aphids in Chile. Agric Téc 53: 91-92.

Rispe C, Pierre JS, Simon JC, Gouyon PH (1998). Models of sexual and asexual coexistence in aphids based on constraints. J Evol Biol 11: 685-701.

Sakai AK, Allendorf FW, Holt JS, Lodge DM, Molofsky J, With KA et al (2001). The population biology of invasive species. Annu Rev Ecol System 32: 305-332.

Sambrook J, Fritsch EF, Maniatis T (1989). Molecular Cloning: A Laboratory Manual, 2nd edn. Cold Spring Harbor Laboratory Press: New York.

Shannon CE, Weaver W (1949). The Mathematical Theory of Communication. University of Illinois Press: Urbana, IL.

Shufran KA, Burd JD, Anstead JA, Lushai G (2000). Mitochondrial DNA sequence divergence among greenbug (Homo- ptera: Aphididae) biotypes: evidence for host-adapted races. Insect Mol Biol 9: 179-184.

Simon JC, Baumann S, Sunnucks P, Hebert PDN, Pierre JS, Le Gallic JF et al (1999a). Reproductive mode and population genetic structure of the cereal aphid Sitobion avenae studied using phenotypic and microsatellite markers. Mol Ecol 8: 531-545.

Simon JC, Delmotte F, Rispe C, Crease T (2003). Phylogenetic relationships between parthenogens and their sexual relatives: the possible routes to parthenogenesis in animals. Biol J Linn Soc 79: 151-163.

Simon JC, Leterme N, Delmotte F, Martin O, Estoup A (2001). Isolation and characterization of microsatellite loci in the aphid species, Rhopalosiphum padi. Mol Ecol Notes 1: 4-5.

Simon JC, Leterme N, Latorre A (1999b). Molecular markers linked to breeding system differences in segregating and natural populations of the cereal aphid Rhopalosiphum padi. Mol Ecol 8: 965-973.

Simon JC, Rispe C, Sunnucks P (2002). Ecology and evolution of sex in aphids. Trends Ecol Evol 17: 34-39.

Starý P, Rodríguez F, Gerding M, Norambuena H, Remaudière $G$ (1994). Distribution, frequency, host range and parasitism of two new cereal aphid pests, Sitobion fragariae (Walker) and Metopolophium festucae cerealium Stroyan (Homoptera, Aphididae), in Chile. Agric Téc 54: 54-59.

Sunnucks P, Chisholm D, Turak E, Hales DF. (1998). Evolution of an ecological trait in parthenogenetic Sitobion aphids. Heredity 81: 638-647.

Sunnucks P, De Barro PJ, Lushai G, Maclean ND, Hales DF (1997). Genetic structure of an aphid studied using microsatellite: cyclic parthenogenesis, differentiated lineages, and host specialization. Mol Ecol 6: 1059-1073.

Sunnucks P, England PR, Taylor AC, Hales DF (1996). Microsatellite and chromosome evolution of parthenogenetic Sitobion aphids in Australia. Genetics 144: 747-756.

Sunnucks P, Hales DF (1996). Numerous transposed sequences of mitochondrial cytochrome oxidase I-II in aphids of the genus Sitobion (Hemiptera: Aphididae). Mol Biol Evol 13: $510-524$.

Tsutsui ND, Suarez AV, Holway DA, Case TJ (2000). Reduced genetic variation and the success of an invasive species. Proc Natl Acad Sci USA 97: 5948-5953.

Tsutsui ND, Suarez AV, Holway DA, Case TJ (2001). Relationships among native and introduced populations of the Argentine ant (Linepithema humile) and the source of introduced populations. Mol Ecol 10: 2151-2161.

Vanlerberghe-Masutti F, Chavigny P (1998). Host-based genetic differentiation in the aphid Aphis gossypii Glover, evidenced from RAPD fingerprints. Mol Ecol 7: 905-914.

Venables WN, Ripley BD (1997). Modern Applied Statistics with $S$-PLUS, 2nd edn. Springer: New York.

Via S (1991). The genetic structure of host plant adaptation in a spatial patchwork: demographic variability among reciprocally transplanted pea aphid clones. Evolution 45: 827-852.

Via S (1999). Reproductive isolation between sympatric races of pea aphids. I. Gene flow restriction and habitat choice. Evolution 53: 1446-1457.

Via S, Hawthorne DJ (2002). The genetic architecture of ecological specialization: correlated gene effects on host use and habitat choice in pea aphids. Am Nat 159: S76-S88.

Vorburger C, Lancaster M, Sunnucks P (2003). Environmentally related patterns of reproductive modes in the aphid Myzus persicae and the predominance of two 'superclones' in Victoria, Australia. Mol Ecol 12: 3493-3504.

Weir BS (1990). Intraspecific differentiation. In: Hillis DM, Moritz C (eds) Molecular Systematics. Sinauer Associates: Sunderland, MA, pp 373-410.

Weir BS, Cockerham CC (1984). Estimating F-statistics for the analysis of population structure. Evolution 38: 1358-1370.

Wilson ACC, Massonnet B, Simon JC, Prunier-Leterme N, Dolatti L, Llewellyn KS et al (2004). Cross-species amplifica- 
tion of microsatellite loci in aphids: assessment and application. Mol Ecol Notes 4: 104-109.

Wilson ACC, Sunnucks P, Hales DF (1997). Random loss of X chromosome at male determination in an aphid, Sitobion near fragariae, detected by an X-linked polymorphic microsatellite marker. Genet Res 69: 233-236.
Wilson ACC, Sunnucks P, Hales DF (1999). Microevolution, low clonal diversity and genetic affinities of parthenogenetic Sitobion aphids in New Zealand. Mol Ecol 8: 1655-1666.

Wilson ACC, Sunnucks P, Hales DF (2003). Heritable genetic variation and potential for adaptive evolution in asexual aphids (Aphidoidea). Biol J Linn Soc London 79: 115-135. 